\title{
The evolution of tooth wear indices
}

\author{
Penny Fleur Bardsley
}

Received: 19 June 2007 / Accepted: 20 December 2007 / Published online: 29 January 2008

(C) Springer-Verlag 2008

\begin{abstract}
Tooth wear-attrition, erosion and abrasion-is perceived internationally as an ever-increasing problem. Clinical and epidemiological studies, however, are difficult to interpret and compare due to differences in terminology and the large number of indices that have been developed for diagnosing, grading and monitoring dental hard tissue loss. These indices have been designed to identify increasing severity and are usually numerical. Some record lesions on an aetiological basis (e.g. erosion indices), others record lesions irrespective of aetiology (tooth wear indices); none have universal acceptance, complicating the evaluation of the true increase in prevalence reported. This article considers the ideal requirements for an erosion index. It reviews the literature to consider how current indices have evolved and discusses if these indices meet the clinical and research needs of the dental profession.
\end{abstract}

Keywords Tooth wear · Tooth wear indices

\section{Introduction}

There is both a clinical and a scientific need to be able to measure tooth wear, and the literature abounds with many methods which can be broadly divided into quantitative and qualitative in nature. Quantitative methods tend to rely on objective physical measurements, such as depth of groove, area of facet or height of crown. Qualitative methods, which rely on clinical descriptions, can be more subjective

\section{P. F. Bardsley $(\bowtie)$}

Birmingham Dental Hospital,

St. Chad's Queensway,

Birmingham B4 6NN, UK

e-mail: Penny.Bardsley@sbpct.nhs.uk if appropriate training and calibration are not carried out but which, with correct safeguards, can be valuable epidemiological tools. In a clinical intra-oral examination, there will be an inclination towards descriptive assessment measures, such as mild, moderate or severe, rather than quantitative measurement, which is easier to perform reliably on a model or in the laboratory. Such methods tend to be more sensitive but do not lend themselves readily to clinical use-especially in epidemiology, where fieldwork data collection is often carried out in an environment lacking sophisticated equipment.

Quantitative and qualitative methods typically utilise grading or scoring systems designed to identify increasing severity or progression of a condition; these are described as indices and are usually numerical. An ideal index should be simple to understand and use, clear in its scoring criteria and be demonstrably reproducible. Its application should be useful for research into the aetiology, prevention and monitoring of a condition, essentially being an epidemiological and clinical tool.

Review of the literature reveals the fact that many different tooth wear indices have been developed for clinical and laboratory use all over the world. Unfortunately, the production of so many indices does not allow for ready comparison of results between different working groups, and this is especially important in epidemiology when trying to define the prevalence of a condition. Confusion is further generated in the literature as the majority of researchers, in their attempts to quantify the amount of tooth tissue loss due to tooth wear, have historically concentrated on one aetiology only, and these indices tend to be surface limited. Often, the wear patterns described do not appear to reflect the aetiology suggested, and this relates to lack of uniformity with tooth wear terminology and translation errors. Many diagnostic indices do not properly reflect the morphological 
defects, and there is little international standardisation. All of these factors complicate the comparison of data and evaluation of the efficacy of preventive and therapeutic measures.

The literature identifies separate indices for use in clinical and laboratory situations and specific indices for attrition, abrasion, erosion and multifactorial tooth wear. There are common threads to all of the indices, such as descriptive diagnostic criteria and criteria for quantifying the amount of hard tissue loss. These generally consider the size of the affected area - as a proportion of a sound surface and/or the depth of tissue loss - often expressed as a degree of dentine exposure.

\section{The clinical measurement of erosion}

The earliest indices shared common, arbitrary criteria, relying on descriptive terms such as slight, mild, moderate, severe and extensive. Restarski et al. [26] developed a sixpoint grading system to evaluate the severity of erosive destruction observed on the lingual surfaces of rat and puppy molars, but concerns were raised with regards to reproducibility. With vague criteria definitions, variability in recording is expected. Each animal was allocated a total score, calculated by summing the mean molar quadrant scores. Whilst producing simple data for analysis, it is acknowledged that averaging scores in this manner leads to the loss of much data. If the number of teeth severely affected is small, the erosion score will be low; but this could mask a significant, localised clinical problem [27].

Eccles [9] originally classified lesions broadly as early, small and advanced, with no strict criteria definitions, thus allowing wide interpretation. Later, the index was refined and expanded, with greater emphasis on the descriptive criteria [10]. It was presented as a comprehensive qualitative index, grading both severity and site of erosion due to non-industrial causes, and is considered as one of the cardinal indices from which others have evolved. In essence, it breaks down into three classes of erosion, denoting the type of lesion, assigned to four surfaces, representing the surface where erosion was detected (Table 1).

Greater accuracy was introduced by Xhonga and Valdmanis [33] who divided erosions into four levels by measurement with a periodontal probe: none, minor (less than $2 \mathrm{~mm}$ ), moderate (up to $3 \mathrm{~mm}$ ) and severe (greater than $3 \mathrm{~mm}$ ). They further differentiated types of erosion by morphological descriptions, such as wedge, saucer, groove and atypical. They did not address the problem of inter- or intra-examiner variability.

\section{The clinical measurement of tooth wear}

It is perhaps significant that the earliest index documented by Broca [4] and used as a foundation for the development of further indices graded horizontal or oblique patterns of occlusal wear without presupposing the aetiology. Smith and Knight [30] introduced the more general concept of measuring tooth wear per se, irrespective of the cause, and since then more recent indices have been developed or modified from Smith and Knight that do not rely on a prior diagnosis and are more clinically relevant. Most of these stress the importance of user training sessions and calibration exercises.

Smith and Knight [30] took Eccles' ideas a stage further, producing the tooth wear index (TWI), a comprehensive system whereby all four visible surfaces (buccal, cervical,

Table 1 Eccles index for dental erosion of non-industrial origin [10]

\begin{tabular}{|c|c|c|}
\hline Class & Surface & Criteria \\
\hline Class I & & $\begin{array}{l}\text { Early stages of erosion, absence of developmental ridges, smooth, glazed surface occurring mainly on labial } \\
\text { surfaces of maxillary incisors and canines }\end{array}$ \\
\hline \multirow[t]{3}{*}{ Class II } & Facial & Dentine involved for less than one third surface; two types \\
\hline & & $\begin{array}{l}\text { Type } 1 \text { (commonest): ovoid-crescentic in outline, concave in cross section at cervical region of surface. Must } \\
\text { differentiate from wedge shaped abrasion lesions }\end{array}$ \\
\hline & & Type 2: irregular lesion entirely within crown. Punched out appearance, where enamel is absent from floor \\
\hline Class IIIa & Facial & $\begin{array}{l}\text { More extensive destruction of dentine, affecting anterior teeth particularly. Majority of lesions affect a large } \\
\text { part of the surface, but some are localised and hollowed out }\end{array}$ \\
\hline Class IIIb & Lingual or palatal & $\begin{array}{l}\text { Dentine eroded for more than one third of the surface area. Gingival and proximal enamel margins have } \\
\text { white, etched appearance. Incisal edges translucent due to loss of dentine. Dentine is smooth and anteriorly } \\
\text { is flat or hollowed out, often extending into secondary dentine }\end{array}$ \\
\hline Class IIIc & Incisal or occlusal & $\begin{array}{l}\text { Surfaces involved into dentine, appearing flattened or with cupping. Incisal edges appear translucent due to } \\
\text { undermined enamel; restorations are raised above surrounding tooth surface }\end{array}$ \\
\hline Class IIId & All & $\begin{array}{l}\text { Severely affected teeth, where both labial and lingual surfaces are extensively involved. Proximal surfaces } \\
\text { may be affected; teeth are shortened }\end{array}$ \\
\hline
\end{tabular}


lingual and occlusal-incisal) of all teeth present are scored for wear, irrespective of how it occurred (Table 2). This avoids the confusion associated with terminology and translation or differences in opinion for diagnosis of aetiology based on clinical findings. Guidelines for using the criteria were produced in a booklet by the authors to aid training and standardisation with other investigators; in cases of doubt, the lowest score is given. Complete enamel loss (score 4) may, however, be misleading, as there is almost always a rim of enamel at the worn surface margins - the colloquial "enamel halo."

This index was the first one designed to measure and monitor multifactorial tooth wear; a further pioneering feature was the ability to distinguish acceptable and pathological levels of wear, by comparison with threshold normal values for the age groups studied. Tooth wear was defined as pathological if the teeth became so worn that they do not function effectively or seriously mar the appearance - before they are lost through other causes - or the patient dies. Results from inter- and intra-reproducibility exercises were within a range regarded as acceptable for epidemiological purposes, and the index appears simple to use clinically - intra-orally or from models and photographs. However, some problems have been identified with the TWI, including the time necessary to apply to a whole dentition, amount of data generated and the comparisons with threshold levels for each age group; the thresholds proposed were high, erring towards understatement rather than exaggerations of pathological wear. Full use of the index as a research tool is not feasible without computer assistance.

Table 2 Smith and Knight tooth wear index [30]

\begin{tabular}{|c|c|c|}
\hline Score & Surface & Criteria \\
\hline \multirow[t]{2}{*}{0} & $\mathrm{~B} / \mathrm{L} / \mathrm{O} / \mathrm{I}$ & No loss of enamel surface characteristics \\
\hline & $\mathrm{C}$ & No loss of contour \\
\hline \multirow[t]{2}{*}{1} & $\mathrm{~B} / \mathrm{L} / \mathrm{O} / \mathrm{I}$ & Loss of enamel surface characteristics \\
\hline & $\mathrm{C}$ & Minimal loss of contour \\
\hline \multirow[t]{3}{*}{2} & $\mathrm{~B} / \mathrm{L} / \mathrm{O}$ & $\begin{array}{l}\text { Loss of enamel exposing dentine for less } \\
\text { than one third of surface }\end{array}$ \\
\hline & I & Loss of enamel just exposing dentine \\
\hline & $\mathrm{C}$ & Defect less than $1 \mathrm{~mm}$ deep \\
\hline \multirow[t]{3}{*}{3} & $\mathrm{~B} / \mathrm{L} / \mathrm{O}$ & $\begin{array}{l}\text { Loss of enamel exposing dentine for more } \\
\text { than one third of surface }\end{array}$ \\
\hline & I & Loss of enamel and substantial loss of dentine \\
\hline & $\mathrm{C}$ & Defect less than $1-2 \mathrm{~mm}$ deep \\
\hline \multirow[t]{3}{*}{4} & $\mathrm{~B} / \mathrm{L} / \mathrm{O}$ & $\begin{array}{l}\text { Complete enamel loss-pulp exposure-- } \\
\text { secondary dentine exposure }\end{array}$ \\
\hline & I & $\begin{array}{l}\text { Pulp exposure or exposure of secondary } \\
\text { dentine }\end{array}$ \\
\hline & $\mathrm{C}$ & $\begin{array}{l}\text { Defect more than } 2 \mathrm{~mm} \text { deep-pulp exposure- } \\
\text { secondary dentine exposure }\end{array}$ \\
\hline
\end{tabular}

A sign of professional confidence in this index is its adopted use by a number of different investigators in the UK looking at tooth wear prevalence and severity $[3,20$, $25,27]$, aetiology and risk $[1,21]$. Other researchers have used it with modifications pertaining to the particular age group being studied. Millward et al. [18] made adjustments to study erosion in the primary and secondary dentitions, excluding cervical surfaces. Subjects were then grouped together to produce three classifications: no or mild erosion - no score $>1$, moderate - at least one tooth in dentition score 2, severe-at least one tooth in dentition score 3 or 4 .

In a survey of elderly people, Steele et al. [31] combined low wear scores representing small losses of enamel and used the worst surface score per tooth as an overall tooth score. Donachie and Walls [7, 8] outlined various flaws in the tooth wear index as an epidemiological tool in the ageing population and suggested a need to increase the sensitivity of TWI at extremes of tooth wear, to take account of the capacity of the elderly to have adequate function in cases of significant wear. They suggested altering threshold values, amplifying scoring criteria and creating a sixth point to distinguish between exposure of secondary dentine and frank pulp exposure.

\section{Development of indices}

Many other indices have been proposed for measuring erosive tooth wear $[2,14,15,17,23]$ which have their roots in the indices of Eccles [10] and Smith and Knight [30]. Linkosalo and Markkanen [15] utilised a qualitative index with listed diagnostic criteria to confirm lesions as erosive and a four-scale grading of severity, relating to involvement of dentine. Their scoring system was modified by Lussi et al. [17] to create an erosive index that has been used widely by European workers to score the facial, lingual and occlusal surfaces of all teeth except the third molars (Table 3).

O'Sullivan [23] proposed a new index for the measurement of erosion specifically in children. The index was qualitative with a broad attempt at quantification noting whether less or more than half of the surface was affected. Every tooth was examined and assigned a three-digit score relating to the site of erosion, severity (grade $0-5$ ) and area of surface affected. O'Brien [22] reported the use of a partial recording system for measuring erosion in children in UK children's dental health surveys, where only the facial and lingual surfaces of the primary and permanent maxillary incisor teeth were scored for erosion. Again, the criteria were mostly qualitative and descriptive, with a broad attempt made to quantify the area involved. 
Table 3 Erosion index according to Lussi $[16,17]$

\begin{tabular}{|c|c|c|}
\hline Surface & Score & Criteria \\
\hline \multirow[t]{4}{*}{ Facial } & 0 & $\begin{array}{l}\text { No erosion. Surface with a smooth, silky glazed appearance, possible absence } \\
\text { of developmental ridges }\end{array}$ \\
\hline & 1 & $\begin{array}{l}\text { Loss of surface enamel. Intact enamel cervical to the erosive lesion; concavity } \\
\text { on enamel where breadth clearly exceeds depth, thus distinguishing it from } \\
\text { toothbrush abrasion. Undulating borders of the lesion are possible and } \\
\text { dentine is not involved }\end{array}$ \\
\hline & 2 & Involvement of dentine for less than half of tooth surface \\
\hline & 3 & Involvement of dentine for more than half of tooth surface \\
\hline \multirow[t]{3}{*}{ Occlusal/lingual } & 0 & $\begin{array}{l}\text { No erosion. Surface with a smooth, silky glazed appearance, possible absence } \\
\text { of developmental ridges }\end{array}$ \\
\hline & 1 & $\begin{array}{l}\text { Slight erosion, rounded cusps, edges of restorations rising above the level of } \\
\text { adjacent tooth surface, grooves on occlusal aspects. Loss of surface enamel. } \\
\text { Dentine is not involved }\end{array}$ \\
\hline & 2 & Severe erosions, more pronounced signs than in grade 1 . Dentine is involved \\
\hline
\end{tabular}

Bardsley et al. [2] pioneered a new, simplified version of TWI [30] when carrying out epidemiological studies on large numbers of adolescents in North West England (Table 4). Tooth wear scoring was essentially dichotomised into the presence or absence of dentine, with even cupping of dentine scoring one. A partial recording system was used, collecting data from 40 surfaces including occlusal surfaces of the four first molar teeth and the labial, incisal and lingual-palatal surfaces of the six upper and lower anterior teeth.

However, despite calibration and training, difficulties were experienced diagnosing dentine exposure in the epidemiological field and there is some debate as to the significance of dentinal cupping when exposed dentine does not relate to significant amounts of tissue loss [12]. In a recent study of Ganss et al. [12], teeth were visually and histologically examined for presence of exposed dentine, and the correlation in accuracy between the two examinations was poor. The diagnosis of exposed dentine is obviously important but may not be accurate from visual examination alone.

Oilo et al. [24] concentrated on a different type of scoring system, with criteria based on treatment need. They criticised the use of indices that used a nonlinear scoring method, claiming calculated mean wear scores can be misleading. Their index was based on Ryge and Snyder's [28] system for evaluating the quality of restorations and

Table 4 Simplified scoring criteria for TWI [2]

\begin{tabular}{ll}
\hline Score & Criteria \\
\hline 0 & No wear into dentine \\
1 & Dentine just visible (including cupping) or dentine exposed for \\
& less than $1 / 3$ of surface \\
2 & Dentine exposure greater than $1 / 3$ of surface \\
3 & Exposure of pulp or secondary dentine \\
\hline
\end{tabular}

had five categories divided into two broad camps; Romeo, Sierra and Mike were satisfactory, whilst Tango and Victor indicated unacceptable levels of wear requiring treatment. All groups except Romeo were subdivided according to degree of dentine exposed and clinical findings such as pain, sensitivity and fracture of restorations, giving the impression of a cumbersome system. Dahl et al. [6] modified it with the introduction of even more categories, with an aim to establish subjective dental criteria for present and future evaluations of tooth wear and the need for treatment. In practice, these indices require experience for reliable use; individuals with differing clinical backgrounds will not get consistent, objective results.

Indices that attempt to visualise, measure and monitor the amount of worn enamel or exposed dentine by difficult direct clinical interpretation [13] and indirectly on accurate, serial study casts which must be retained $[5,11,29,32]$ have been described. Larsen et al. [14] recommended a new clinical index based on a combination of clinical examination, photographs and study casts, with complicated qualitative and quantitative criteria. Plaque-free teeth were clinically examined and photographed prior to taking silicone impressions for epoxy resin casts. They considered clinical and photographic data to be supplemental with final wear classification based on visual inspection of casts at $\times 10$ magnification. Each tooth surface was scored, with six grades of erosion severity modelled from Smith and Knight [30]; the index and its criteria are complicated and time consuming.

\section{Conclusion}

Review of the literature on indices for tooth wear (or erosion) is confusing; there are too many indices proposed and used, with lack of standardisation in terminology. There are many epidemiological studies reported, but it is difficult 
to quantify the increases in prevalence reported internationally, as results are not easily comparable. It is doubtful whether any of the indices described are sensitive enough to monitor all but the most severe changes in tooth wear clinically and these cannot be used to measure a rate of wear [19]. It is a challenge to try to develop a simple index that can be used clinically to assess progression of wear.

To date, there is not one ideal index that can be used for epidemiological prevalence studies, clinical staging and monitoring, and it may be necessary to accept that one simple index does not yet exist to meet all requirements of both clinical and research teams. There should, however, be an aim for indices that can be relevant to both fields and can be used internationally in order to strengthen knowledge of dental erosion.

Conflict of interest statement The author declares that she has no conflict of interest.

\section{References}

1. Asher C, Read MJ (1987) Early enamel erosion in children associated with the excessive consumption of citric acid. Br Dent J 162:384-387

2. Bardsley PF, Taylor S, Milosevic A (2004) Epidemiological studies of tooth wear and dental erosion in 14-year old children in North West England 1. The relationship with water fluoridation and social deprivation. Br Dent J 197:413-416

3. Bartlett DW, Coward PY, Nikkah C, Wilson RF (1998) The prevalence of tooth wear in a cluster sample of adolescent schoolchildren and its relationship with potential explanatory factors. Br Dent J 184(3):125-129

4. Broca $P$ (1879) Instructions rélatives a l'étude anthropologique du systéme dentaire. Bull Soc Anthrop Paris 2(3):128-163

5. Carlsson GE, Johannson A, Lundqvist S (1985) A follow up study of 18 subjects with extensively worn dentitions. Acta Odontol Scand 43:83-90

6. Dahl BL, Oilo G, Andersen A, Bruaset O (1989) The suitability of a new index for the evaluation of dental wear. Acta Odontol Scand 47:205-210

7. Donachie MA, Walls AW (1995) Assessment of tooth wear in an ageing population. J Dent 23(3):157-164

8. Donachie MA, Walls AW (1996) The tooth wear index: a flawed epidemiological tool in an ageing population group. Community Dent Oral Epidemiol 24(2):152-158

9. Eccles J (1978) The treatment of dental erosion. J Dent 6:217-221

10. Eccles JD (1979) Dental erosion of nonindustrial origin. A clinical survey and classification. J Prosthet Dent 42:649-653

11. Fareed K, Johansson A, Omar R (1990) Prevalence and severity of occlusal tooth wear in a young Saudi population. Acta Odontol Scand 48(4):279-285
12. Ganss C, Klimek J, Lussi A (2005) Accuracy and consistency of the visual diagnosis of exposed dentine on worn occlusal/incisal surfaces. Caries Res 40:208-212

13. Hugoson A, Bergendal T, Ekfeldt A, Helkimo M (1988) Prevalence and severity of incisal and occlusal tooth wear in an adult Swedish population. Acta Odontol Scand 46(5):255-265

14. Larsen IB, Westergaard J, Stoltze K, Larsen AI, Gyntelberg F, Holmstrup P (2000) A clinical index for evaluating and monitoring dental erosion. Community Dent Oral Epidemiol 28:211-217

15. Linkosalo E, Markkanen H (1985) Dental erosions in relation to lactovegetarian diet. Scand J Dent Res 93:436-441

16. Lussi A (1996) Dental erosion; clinical diagnosis and case history taking. Eur J Oral Sci 104:191-198

17. Lussi A, Schaffner M, Hotz P, Suter P (1991) Dental erosion in a population of Swiss adults. Community Dent Oral Epidemiol 19 (5):286-290

18. Millward A, Shaw L, Smith AJ, Rippin JW, Harrington E (1994) The distribution and severity of tooth wear and the relationship between erosion and dietary constituents in a group of children. Int J Paediatr Dent 4(3):151-157

19 Milosevic A (1994) Tooth wear in young people: prevalence and risk factors. Ph.D. thesis, University of Liverpool

20. Milosevic A, Young PJ, Lennon MA (1994) The prevalence of tooth wear in 14-year-old school children in Liverpool. Community Dent Health 11(2):83-86

21. Milosevic A, Lennon MA, Fear SC (1997) Risk factors associated with tooth wear in teenagers: a case control study. Community Dent Health 14(3):143-147

22. O'Brien M (1994) Children's dental health in the United Kingdom 1993. Office of Population Censuses and Surveys, Her Majesty's Stationary Office, London

23. O'Sullivan EA (2000) A new index for the measurement of erosion in children. Eur J Paediatr Dent 1:69-74

24. Oilo G, Dahl BL, Hatle G, Gad AL (1987) An index for evaluating wear of teeth. Acta Odontol Scand 45:361-365

25. Poynter ME, Wright PS (1990) Tooth wear and some factors influencing its severity. Restorative Dent 6:8-11

26. Restarski JS, Gortner RA, McCay CM (1945) Effect of acid beverages containing fluorides upon the teeth of rats and puppies. J Am Dent Assoc 32:668-675

27 Robb ND (1992) Epidemiological studies of tooth wear. Ph.D. thesis, University of London

28. Ryge G, Snyder M (1973) Evaluating the clinical quality of restorations. J Am Dent Assoc 87:369-377

29. Seligman DA, Pullinger AG, Solberg WK (1988) The prevalence of dental attrition and its association with factors of age, gender, occlusion and TMJ symptomatology. J Dent Res 67:1323-1333

30. Smith BG, Knight JK (1984) An index for measuring the wear of teeth. Br Dent J 156:435-438

31. Steele JG, Walls AW, Ayatollahi SM, Murray JJ (1996) Major clinical findings from a dental survey of elderly people in three different English communities. Br Dent J 180:17-23

32. Woda A, Gourdon AM, Faraj M (1987) Occlusal contacts and tooth wear. J Prosthet Dent 57:85-93

33. Xhonga FA, Valdmanis S (1983) Geographic comparisons of the incidence of dental erosion; a two-centre study. J Oral Rehab 10:269-277 